\title{
Collaborative knowledge and intellectual property: an action learning conundrum
}

\section{Elliott, T}

http://hdl.handle.net/10026.1/10823

10.1080/14767333.2017.1363717

Action Learning: Research and Practice

Taylor \& Francis (Routledge)

All content in PEARL is protected by copyright law. Author manuscripts are made available in accordance with publisher policies. Please cite only the published version using the details provided on the item record or document. In the absence of an open licence (e.g. Creative Commons), permissions for further reuse of content should be sought from the publisher or author. 


\title{
ABSTRACT
}

\section{Collaborative knowledge and intellectual property: an action learning conundrum}

\author{
Tish Elliott \& Mike Pedler
}

Notes on contributors:

Tish Elliott is a Social Work Practice Educator and Lecturer at Plymouth University. She is an Associate of the Centre for Action Learning Facilitation. www.c-alf.org

Mike Pedler is Emeritus Professor at Henley Business School, University of Reading, UK and Founding Editor of Action Learning: Research \& Practice, the international journal for action learning from Routledge, Taylor \& Francis. www.tandfonline.com/actionlearning

\begin{abstract}
If everyone is contributing, if action learning involves collective learning, then new knowledge is created through a collaborative process. This is not expert knowledge and no 'one truth' is produced, this is a collective knowledge arising from a common purpose and a shared quest. Such knowledge continues to evolve without the intention to fix or commodify. Collaborative knowledge can be a source of innovation and sustainability, and as such a key process in the knowledge economy and the learning society. However, whilst knowledge economies require constant innovation to promote economic development and trade, this often takes the form of intellectual property production (IP), with the consequent establishment and policing of IP rights, notions that are antithetical to collaborative knowledge creation.
\end{abstract}

Keywords: Collaborative knowledge, intellectual property, social work practice, the knowledge economy

\section{Introduction}

"All meaningful knowledge is for the sake of action, and all meaningful action for the sake of friendship." John Macmurray The Self as Agent 1953 quoted by Revans (2011: ix)

This paper explores some incongruities between intellectual property ownership and the outcomes of action learning. Adopting an "insider" approach to action learning research (Brannick \& Coghlan 2007; Coghlan \& Shani 2008), we use our joint and separate voices to survey these different perspectives on knowledge creation. Having begun with some practice-based evidence, we develop the argument first by summarising the characteristics of collaborative knowledge based on our own experiences in action learning sets. We then proceed via individual personal reflections: the first author on the incongruities arising from her practices in the two knowledge worlds of academia and social work, and the second with a more distanced discussion of different forms of knowledge in the knowledge economy. Our overall purpose is to understand more about how action learning can contribute to useful knowledge innovation in the wider economy whilst at the same time holding to the values of inclusivity, co-production and common ownership. We conclude with a quote from Banksy, who has his own take on this issue. 
We begin with a debate between colleagues about the use of written action learning materials seen on the one hand as free goods, to be used wherever thought fit, and on the other, as personal property, not to be used without permission and perhaps payment. Subsequently this sharp distinction became part of an on-line action learning set involving three people - A, B \& C:

A: The Incongruity of IP and AL! So, how does Intellectual Property work in action learning? .....

$\mathrm{B}$ : AL is about exchange and working together - how do we determine what's mine and what's yours? Knowledge creation involves giving and taking - how does this work?

C: How do we work with other partners, for example X (a client), how do we hang on to what is ours, whilst recognising that only they can develop and customise the materials to fit their situation?

B: In X they have different ideas about IP; it's a question of what can they use ... or misuse? What is created that is new? This is Innovation Management.

A: If everyone is contributing, it is collective learning; AL creates new knowledge through this collective process. There is no expert knowledge coming out of this because it is a collaborative process and ...... this is what makes it sustainable ...

C. Why and how does this make it sustainable?

A: ... it has a common purpose and not an intention to commodify, as in a capitalist economy.

B: Creating knowledge in the set comes via a common consciousness - this is the source and this is what is sustainable. As a facilitator I have to give this picture to the set ... Building up consciousness; it is an attitude, an attitude of exploring together.

The conversation continued but the conundrum is unresolved. It has however sparked further reflection on the nature of collaborative knowledge creation and how this sits with the values of social work and wider co-production of knowledge (Gibons et al, 1994; Beresford, 2015).

\section{Collaborative knowledge ....}

"I'm for mystery, not interpretive answers. ... The answer is never the answer. What's really interesting is the mystery. If you seek the mystery instead of the answer, you'll always be seeking." Ken Kesey "The Art of Fiction" 1994

Action learning is concerned with mysteries or as Revans called them "problems/opportunities where no solution can possible exist already... " (2011: 24). Critical to this search is "questioning insight" or "the ability to pose useful questions when there can be no certainty as to what next then might happen" (2011: 25). The action learning set is the principal enabler for this demanding work and, in the dialogue of the set, members pool their understandings of what is already known and collaborate to develop new insights and knowledge. The insights and understandings that emerge in this process and in this particular context seem very different to more familiar forms of knowledge. On the basis of our shared experiences of working in and with action learning sets, we observe the following characteristics of this collaborative knowledge:

First, it is a collective phenomenon, to which people contribute as individuals but which becomes something more than these individual contributions. 
Secondly, as evolving within the set discussions and the associated cycles of action and learning, the primary purpose of collaborative knowledge is to promote further action and learning by and for members. This is the common purpose of the set.

Thirdly, collaborative knowledge is situated knowledge. It is created in a particular place by a particular practice community and is therefore only available in this unique "social co-participation" (Hanks AF in Lave \& Wenger 1991: 14). This local making makes it a communal property belonging to, and only fully understandable to, the people in this situation.

Fourthly, collaborative knowledge can be described warm, even hot; both as arising from the immediacy of the content of the insight or discovery and because of the potentially continuous coproduction process. Insights and understandings are created "all in a mess of one another's labours" (Samuel Hartlib in Pedler 2012: 5), and this is knowledge forged in comradeship.

Fifthly, collaborative knowledge is fluid in form, and evolving. The flow of conversation made up of reflections, tentative understandings, possible meanings, partial insights, moments of silence and so on, does not produce a set of definitive outputs as much as a soup of possibilities. The collaborative learning process thus contains the potentials both to be innovative and self-sustaining.

Sixthly, because it is concerned with continuing situations, collaborative knowledge tends to be incomplete and partially formed. This is in contrast to what Revans called "P" or the "stock of programmed propositions" arising from the resolution of previous problems (2011:2). Unlike collaborative knowledge, programmed or expert knowledge is presented as complete and is therefore easily shared and made available to outsiders.

Finally, collaborative knowledge is what emerges from a particular state of collective mind and from the application of what Revans called "Q characteristics", including starting from ignorance, from what is not understood, from conjecture, from competing interpretations and from radical inventiveness (1982: 764/5). Questioning insight, or Q, is fundamental in the application of P to practice in a profession which "promotes social change and development, social cohesion, and the empowerment and liberation of people" (IFSW, 2014) in the context of rapidly changing legislation, socio-political and economic climates.

\section{.... and Intellectual Property}

However, even as we make contributions to this collective and collaborative knowledge, we also take away our own individual meanings. Collaborative knowledge production offers the potential for the creation of privately owned IP:

\section{A thought experiment: The good action learner}

Supposing that an action learning set member returns home after a stimulating session and sits down to produce some useful P - a handout, some Powerpoint slides, a manual, a book. How will she then feel when just the next month, a professional colleague, but not a fellow set member, shows almost identical slides, branded with their own name? How does he feel when the book, so laboriously crafted, appears somewhere overseas in translation without agreement or acknowledgement?

Q1: Is our action learner justified in feeling moral outrage at this turn of events?

Or, should he feel that, even as he took the vital shoots of his ideas from his set, this evidence of free circulation should be greeted with joy and satisfaction?

Q2: Should she have been very careful to copyright and brand her goods before publishing them? 
Or should she have proposed to the set that these goods should be their communal IP and opened the discussion of further dissemination with fellow members?

These questions reflect the conundrum addressed by this paper. They continue to underlie the reflections on practice that follow and the later discussion on matters of IP, privately owned and communal, practical and moral.

\section{Knowledge and practice - the social worker's perspective}

I began thinking about the ownership of knowledge in an action learning context at the $4^{\text {th }}$ International Action Learning Conference in April 2014 when an interesting, if somewhat heated, debate arose about whether someone was speaking their knowledge from the viewpoint of 'academic' or 'practitioner'. Jan Fook (2002) recognises the limitations of such binary thinking as creating oppositional relations, or unhelpful dichotomies, between 'us' and 'them'. In this instance I was wary of constructing a polar opposite between 'academic' knowledge and 'practice' knowledge.

Competitiveness around the ownership of knowledge, the notion that one person's knowledge may be seen as more valuable than another, seems incongruent with action learning, and with social work values. Academic knowledge is a particular sort of expert knowledge or P (Revans 2011: 2/3). Service users' experiential knowledge, from lived experience, is equally valuable and indeed central to collaborative knowledge creation in social work practice. As Beresford concludes "service users (and carers) are unique in 'knowing' what it is like to be on the receiving end of policy and provision. Unfortunately, such knowledge is still not granted parity with more traditional sources." (Beresford, 2015:65). When knowledge is purely 'academic' how can it be of any use to the people, the families, we work with and those who care for them? Social work places increasing emphasis on co-production and participatory social policy to strengthen the voice of service users and carers in knowledge creation.

Jan Fook critiques "modernist notions of power [which] seem to conceptualise power as a 'commodity', that is, a material entity which can be traded or given away, or transferred from one person to another." (2002, p.48). She cautions against seeing empowerment as a commodity whereby if one group gains power another must lose power. Such socially constructed polarization can be viewed as a contributing factor in the process of 'othering' (Harrison \& Melville, 2010) whereby one group's identity and knowledge is seen not just as different to, but lesser than, that of another group. In social work practice, anti-oppressive approaches seek to avoid binaries which pathologise and divide people across simplistic notions of identity, and challenge the use of language which negatively stereotypes or labels one group's identity as less worthy than the other - 'service user' or 'professional', 'third world' or 'civilised', 'gay' or 'straight', 'immigrant' or 'citizen' . The critical application of knowledge to practice, and deconstruction of the source of that knowledge (Sellick et al, 2002), is core to the social work mission of promoting social justice and human rights. At the heart of this is a commitment to using inclusive action research and action learning methodologies in both practice and academic worlds (Elliott et al, 2005; Bellinger and Elliott, 2011) working collaboratively with service users, students, practitioners and other programme stakeholders in the investigation and co-production of new knowledge.

Such action learning techniques can be used in both practice and academic settings as a peer group supervision tool which supports social workers and social work trainees to examine their judgments and ways of seeing the world. Participants use the set to analyse their critical thinking when making professional decisions in complex and uncertain social care settings and in high risk safeguarding situations (Abbott and Taylor, 2013). If practitioners work in a purely technical rational way, without critical appraisal of the knowledge base they are using, then practice is mechanistic and tick box - it is 'academic' in the sense of being abstract rather than in the sense of being applied with the criticality required to promote the rights, strengths and expertise of people with care and support needs. Action learning is a method which seeks to avoid "othering"; it facilitates inclusivity and co-production whilst encouraging learning, seeing things from different, more challenging, perspectives. It 
encourages different voices and it values diversity, as essential ingredients for rich learning in the coproduction of new knowledge.

Reflecting on both my academic and social work practice roles in this way has produced a series of questions for further action learning discussion: "How do I manage different ideologies and procedures surrounding the ownership and sharing of knowledge? How do I manage the organisational demands and procedures that govern intellectual property ownership in different settings? How do I tackle my personal dilemma of this not sitting easily with Revans' beliefs around questioning programmed knowledge (rather than selling it) nor with the social work core mission of promoting equality, human rights and social justice, ensuring 'expert' knowledge is socially deconstructed and education accessible to all?"

For me knowledge is relational, not owned (Ruch et al, 2010), not procedural nor a 'professional gift' whereby support is defined by professionals and given as a unilateral gift to 'needy' people. My preferred conceptualisation of knowledge draws from the citizenship model (Duffy, 2009), a newer paradigm for public services where support is treated as an entitlement, which can be shaped and driven by the citizen in the context of their community life. Knowledge grows out of shared ideas and collaborative investigation. Knowledge builds on what works, is inclusive rather than exclusive, and is service user led (Bellinger and Elliott, 2011). Knowledge is power (Foucault, 1970) therefore withholding or selling knowledge is withholding power, is excluding and oppressive, unjust in action and incongruent with social work values.

The internet is making knowledge more freely accessible, so when and how are we justified in selling it, owning it and defining its academic level (of prestige, or of expertise)? Do not the principles of action learning - beware expert knowledge - and the core belief in questioning programmed knowledge mitigate against such ownership? A professional understanding of safe practice confirms the need for quality assurance and an assessed level of practice in action learning facilitation: I can 'return the investment' in my training by continuing to use my action learning facilitation skills to support front line social workers in action learning sets to build their emotional resilience in making critical practice decisions. How do I square IP ownership with my altruistic ideologies? These questions are very pertinent at this point in my life as I move from being a public service employee to working independently in the private sector. I value action learning as a shared learning environment where we can examine such questions of whether or when it is ethical to place a 'copyright' on action learning material and when it is freely available, creating our own personal political 'theories for practice' (Fook, 2007). This remains though, a wicked problem.

\section{Valuing $P$ in the Knowledge Economy}

A different light can be thrown on this problem by looking at it from perspective of the interests of the wider community and in particular from what is called here the knowledge economy. This involves reconsidering the place of $\mathrm{P}$. Revans acknowledged the value of $\mathrm{P}$, albeit rather dismissively: "We do NOT reject P; it is the stuff of traditional instruction" (2011: 3 original capitals). This dismissal is to be understood in the context of his making the case for Q: the aim of action learning being to encourage managers and other practitioners not to rely on past experience, but to think differently and to ask fresh questions. Equally, because he is concerned to put forward an alternative to traditional education as instruction, he warns repeatedly against experts and remains vigilant against all those, such as management teachers, who might seek to turn Q into P. He wants action learners to be in charge and to get their $\mathrm{P}$ from each other as peer knowledge rather than turning to those who might not act, or be perceived as, peers. Thus Revans always seeks to downplay the value of $\mathrm{P}$ and to take it for granted. 
In fact, of course, the value of $\mathrm{P}$ is obvious, not least in Revans' personal erudition and throughout his writings. Including the products of the Enlightenment project and the development of the arts and sciences, $\mathrm{P}$ is the foundation of numerous obvious benefits of modern life. As the basis of expert knowledge in its many and proliferating varieties; it can be codified, expressed formally, transmitted easily and made widely available. A vaccine for smallpox, a process for making steel, an idea for educating children and recipe for Christmas cake all embody knowledge that can work, and that can be useful to others at a distance. This also means that $\mathrm{P}$ is readily turned into IP, which copyrights knowledge that has been proven through being exposed to scrutiny and with some evidential standing.

Use of the term "knowledge economy" has greatly increased since its promotion by Peter Drucker in 1969 as describing an economy where knowledge production and exploitation are the basis for creating valuable goods and services. In contrast to agricultural or industrial economies which are physically labour intensive, and together with allied notions such as the "Information Age" (Castells 1999) and the "Learning Society" (Stiglitz \& Greenwald 2014), knowledge economies run on human know-how or "human capital": the stock of people's talents, skills and creative abilities. Of these abilities, innovation is one of the most prized, not least as underpinning the "competitive advantage" of firms and nations (Porter 1998).

As a principal means of maintaining this advantage, Intellectual Property or IP rights are central to the knowledge economy. As applied to songs, papers, translations, inventions, apps and the many forms of branded goods, IP is a critical part both of the livings of individuals and of trade with other economies. The term dates back to the 18th Century when patents were important as a means of protecting inventors and investors. Since then IP has grown in both its range or application and in its economic importance regarding the development of new ideas and innovations in general. This is so much so that it has now become both a legal and a moral right; Article 27 of the Universal Declaration of Human Rights asserts that: "everyone has the right to the protection of the moral and material interests resulting from any scientific, literary or artistic production of which he (sic) is the author" (http://www.un.org/en/universal-declaration-human-rights/).

\section{But what has IP to do with action learning?}

Despite its being a cornerstone of modern economic life, there are a number of practical and ideological difficulties with the notion of intellectual property. IP rights are often contentious and difficult to apply: 18th Century figures like Richard Arkwright battled to get their mechanical inventions patented and today's musicians and artists struggle to establish and maintain their copyrights. Modern methods of reproduction and dissemination, especially via the internet, further weaken the power and scope of practical and legal protections. IP can also over-protect and be used to restrain, restrict and monopolise in ways that prevent innovation and the free flow of ideas. A third criticism is especially important from the perspective of action learning, with which IP is apparently antithetical, especially because of the extent to which IP underpins and reinforces the power of expert knowledge.

Action learning can be seen as a response and a reaction to the rise of the expert knowledge that has accompanied the economic, social and political advances of the last two or three centuries. Foucault proposes that power is immanent and omnipresent in every use of knowledge, and his use of "knowledges" is to assert this multivocal nature of knowing (Foucault in Sheridan 1980:161-3). However, whilst different versions of truth are potentially available, the voices of higher status people such as experts, may often prevail. Habermas (in Egmose: 2015: 46-49) suggests that expert knowledge has become the dominant way of thinking in the modern era. He criticises expert knowledge as cognitive, instrumental and as offering a very limited view of human rationality. "Full human rationality" requires the bringing together of three different realities: the objective concerning the factual world; the social of cultural norms for social actions; and the subjective of the individual's own thoughts, feelings, hopes and aspirations. Habermas' proposal for integrating these realities in a way which embodies the equality of status and freedom of voice essential to full discourse is the 
"ideal speech community". Whilst action learning sets aspire to be such ideal speech communities, the immanence of power in human relationships means that asymmetries and inequalities will still exist even here (a recognition responsible for the post-Revans "Critical action learning" aimed at sharpening this awareness and supporting efforts to equalise voice (Vince 2009; 2012)).

In championing the power of the practitioner voice, Revans understood earlier than most people about the disabling effects of expert power on the learner's freedom of thought and action. His critique of expert knowledge is thus not based formally on critical theory, but on the practical and pragmatic grounds that impersonal, technical knowledge is inadequate in the face of the truly difficult problems: $"$... the domain of the leader ... is charged with unanswerable questions as well as unformulated ones..." (1982: 712/3 Original italics). Expert knowledge may prove valuable, but it is never sufficient in uncertain circumstances. Moreover, he makes it clear that leaders and other action learners always carry personal and moral responsibility for their choices and actions. The danger of expert power-knowledge is that it might override the personal moral imperative: "The undue intervention of experts carrying no personal responsibility for the real-life actions that bring the set together is, at best, ambiguous; in general, opinionative; and at worst, reactionary" (Revans 2011: 8)

\section{Conclusion: Who owns Banksy?}

We conclude that action learning is ideologically and systemically unsympathetic to IP and its close relative, expert knowledge. As we have noted, and in contrast with expert knowledge, collaborative knowledge is not easily transportable or even understandable outside the particular context in which it is generated. Produced by the common purpose and collective endeavour of the set, it is intended to encourage and aid action and learning in difficult circumstances. When the action learning set works well, and some new insight emerges, this can happen on the site of the individual or in the group as a collective acknowledgement, or both. The aim of the peer learning community is to generate new collaborative knowledge in a process quite different in intent from the production of $\mathrm{P}$ or expert knowledge. There is no claim to "one truth" and there is no intent to commodify. Moreover the product is different: knowledge developed in this dialogue tends towards the fluid, evolving over cycles of action and reflection and essentially never complete.

Nevertheless, the conundrum does not go away. Even given a foundational hostility towards IP as the incarnation of expert knowledge, this does not quite rule out the possibility of contributions arising from the collaborative knowledge produced in action learning. As partly seen in earlier examples $\mathrm{P}$, and IP, can be distilled from the collaborative knowledge process either by individuals, by combinations of individuals, or by the set acting as collective. What is wrong with this? In its purpose of encouraging action and learning in problematic conditions, the generation of collaborative knowledge in action learning offers something that goes beyond the scope of current expertise. Given the thirst for innovation and new knowledge in the knowledge economy, the potential of action learning to find new ideas and fresh questions is an attractive proposition in itself, and yet it can scarcely stay there. As the experiences of new action are reflected upon and learned from, there is the possibility of this action learning process leading to new $\mathrm{P}$, and therefore to new IP. This raises new questions about how is collaborative knowledge turned into P in order to become IP-able.

We began by puzzling over the challenge of intellectual property ownership in the context of the collaborative knowledge process of action learning. Jan Fook's advice is to avoid such binaries in our language and thinking, and seek rather to create an understanding of co-production in meaning - out of which, we conclude, action may be taken to create an 'economy for the common good'. Whilst the conundrum remains unresolved in any final way, action learning and other methodologies promoting inclusivity and partnership in the quest for new knowledge, imply that the journey of learning together through inquiry and discovery is as important as any new collected knowledge generated. How to deal with the question of intellectual property is perhaps a problem that can only be determined where it arises. A final thought comes from Banksy, explaining his position following an attempt by someone to steal and sell murals which had been 'gifted' to the local community: 
"For the sake of keeping all street art where it belongs I'd encourage people not to buy anything by anybody unless it was created for sale in the first place."

Banksy, Mail Online, February 23, 2013

\section{References}

Abbott, C. and Taylor, P. (2013) Action Learning in Social Work. London: Sage.

Banksy Interview (2013) "'Stolen' Banksy mural withdrawn from sale at U.S. auction house following storm of protest as mysterious new graffiti appears in its place" Mail Online February 23, 2013. http://www.dailymail.co.uk/news/article-2283475/Stolen-Banksy-muralwithdrawn-sale-U-S-auction-house-following-storm-protest-mysterious-new-graffiti-appearsplace.html

Bellinger, A., and Elliott, T. (2011) "What are you looking at: The Potential of Appreciative Inquiry as a Research Approach for Social Work" British Journal of Social Work Vol. 41. pp. 708-725.

Brannick T \& Coghlan D (2007) "In defense of being "native": The case for insider academic research" Organizational Research Methods 10: 1 59-74

Beresford, P. (2015) Involving people, co-production and advocacy in D. Walden (Ed) Reimagining Adult Social Care.Dartington:Ripfa pp 64-68.

Castells, M. (1999) The Information Age, Volumes 1-3: Economy, Society and Culture. Cambridge (Mass.); Oxford: Wiley-Blackwell.

Clancy, T. (n.d.). BrainyQuote.com. Retrieved March 8, 2016, from BrainyQuote.com Web site: http:/ / www.brainyquote.com/quotes/quotes/t/tomclancy290236.html

Coghlan D, Shani AB (2008)" Insider action research: The dynamics of developing new capabilities" in Reason P \& Bradbury H (Eds). The Sage Handbook of Action Research pp 643-655.

Duffy, S. (2009) The Citizenship Model. Sheffield: The Centre for Welfare Reform.

Drucker P (1969). The Age of Discontinuity; Guidelines to Our Changing Society. New York: Harper and Row

Egmose, J. (2015) Action Research for Sustainability: Social Imagination between Citizens and Scientists Farnham: Ashgate.

Elliott, T., Frazer,T., Garrard,D., Hickinbotham,J., Horton,V., Mann,J., Soper,S.,Turner,J., Turner,M., Whiteford, A. (2005) 'Practice Learning and Assessment on BSc(Hons) Social Work: Service User Conversations', Social Work Education Journal, Vol.24. June, 2005.

Fook, J. (2002) Social Work: Critical Theory and Practice. London:Sage

Fook, J. (2007) 'Reflective Practice and Critical Reflection' in J. Lishman (Ed) Handbook for

Practice Learning in Social Work and Social Care: Knowledge and Theory London: Jessica Kingsley pp.363-375.

Foucault, M. (1970) The Order of Things. London: Tavistock

Gibbons, M. Limoges C., Nowotny, H., Schwartzman, S., Scott P., and Trow, M. (1994) The new production of knowledge: the dynamics of science and research in contemporary societies

London: Sage

Harrison, G. and Melville, R. (2010) Rethinking Social Work in a Global World Basingstoke:

Palgrave Macmillan.

International Federation of Social Workers (2014) Global Definition of the Social Work Profession approved by the IFSW General Meeting and the IASSW General Assembly in July 2014 Kesey, K. (1994) "The Art of Fiction" Interview by Robert Faggen The Paris Review No. 130 Spring 
Lave, J. \& Wenger, E. (1991) Situated Learning: Legitimate Peripheral Participation New York: Cambridge University Press.

Pedler, M. (2012) "All in a knot of one another's labours: self-determination, network organising and learning" Action Learning: Research and Practice Vol. 9, No. 1, March, 5-28 Porter M (1998) The Competitive Advantage of Nations London: Palgrave Macmillan Reason, P. \& Bradbury, H. (2008) "Introduction" to Reason \& Bradbury (Eds.) The Sage Handbook of Action Research 2nd Ed. London: Sage pp1-10

Revans, R.W. (1982) The Origins \& Growth of Action Learning Bromley: Chartwell-Bratt Revans, R.W. (1989) Action learning: New techniques for management. London: Blond \& Briggs.

Revans, R.W. (2011) ABC of Action Learning Farnham: Gower Ruch, G., Turney, D. \& Ward, A. (2010) Relationship-based Social Work: Getting to the Heart of Practice. London and Philadelphia:Jessica Kingsley.

Sellick, M., Delaney, R. and Brownless, K. (2002) 'The Deconstruction of Professional Knowledge: Accountability without Authority.' Families in Society Vol. 83(5), pp.493-498.

Sheridan A (1980) Michel Foucault: The will to truth London: Tavistock Stiglitz J \& Greenwald B (2014) Creating a Learning Society: A New approach to Growth, Development, and Social Progress New York: Columbia University Press Vince, R. (2008) 'Learning-in-action' and learning inaction: advancing the theory and practice of critical action learning" Action Learning Research and Practice, 5(2): 93-104 Vince R (2012) "The contradictions of impact: action learning and power in organizations" Action Learning: Research E Practice 9(3) 209-218 